\title{
Antecedents of Passive-Aggressive Behavior as Employee Deviance
}

\author{
D'Lisa N. McKee \\ Quinnipiac University
}

Using the framework of deviant behavior, this paper examines passive-aggression and proposes antecedents that may influence how an individual acts when he or she chooses to engage in deviant behavior. The personality traits of extraversion and high self-monitoring are proposed as predictors of passive-aggressive behavior, and the psychological contract breech is also proposed as a situational predictor of passive-aggression. Using established typologies of both deviant behavior (i.e. Robinson \& Bennett, 1995) and aggressive behavior (i.e. Binning \& Wagner, 2002), this paper attempts to identify one type of aggressive deviant behavior and understand its causes.

Keywords: Employee Deviance, Passive-Aggression, Aggressive Behavior

\section{INTRODUCTION}

Employee misbehavior in organizations is a well-documented phenomenon, resulting in research in areas such as counterproductive work behaviors (Sackett, 2002), incivility (Andersson \& Pearson, 1999), sabotage (Crino, 1994), and abusive supervision (Tepper, 2000; 2007). Academic interest spans studies focusing on one singular behavior, such as theft (Greenberg, 1990), to studies of entire sets of behaviors (i.e. Robinson \& Bennet, 1995) in an effort to understand the effects of these actions. Deviant employee behavior can cost companies millions of dollars, and can be disruptive to organization and its members. Consequently, research is motivated to understand both the antecedents and consequences of these behaviors (Bennett \& Robinson, 2003).

Many types of employee deviance, such as theft, sabotage, or abusive supervision, are easily recognizable to an observer. While there has been a great deal of research focusing on that which is more easily observed, some types of employee deviance can more difficult to observe or detect, even when they have significant consequences for the organization or its members. Focusing on aggressive behaviors, Schat and Kelloway maintain that non-physical workplace aggression is the most common type of aggression, despite the fact it receives less attention (2005) than physical aggression. One subset of this non-physical behavior is passive-aggression, which is an intentionally covert type of deviance that occurs when an individual purposefully withholds an action with the intent of doing harm (Binning \& Wagner, 2002). As a deviant behavior, passive-aggression can range from acts of incivility to complete sabotage. Due to their nature, passive-aggressive behaviors might not even appear to be deviant when they actually are. Given that passive-aggressive deviance can be damaging to the organization or its employees, it is important to understand its causes. 
The purpose of this paper, within the context of deviant workplace behavior, is to identify antecedents of passive-aggressive behavior. Using a framework of aggressive deviance and the definition of passiveaggressive behavior (i.e. Binning \& Wagner, 2002), this paper proposes both situational and personality trait based factors that may influence an employee's behavioral choice in regard to what type of deviant behavior they choose to engage in. By associating the covert and passive nature of passive-aggressive behavior with personality traits such as extraversion and self-monitoring, the first goal of this paper is to propose specific personality traits that may make an individual more likely to engage in passiveaggression rather than other types of deviance. Similarly, the second goal is to consider situational forces, specifically the psychological contract breech, which may be more likely to encourage passive-aggressive behavior in employees who engage in deviance. By understanding the precursors to passive-aggression, this knowledge can help identify contexts that might cause it, in an effort to mitigate and minimize impact on both the organization and its employees.

\section{Aggressive Workplace Behavior}

Workplace aggression has received a great deal of attention in the literature (see Ferris et al., 2016). Workplace aggression is a "behavior by an individual or individuals within or outside an organization that is intended to physically or psychologically harm a worker or workers and occurs in a work-related context" (Schat \& Kelloway, 2005, p. 191). While the term aggression might inspire images of physical acts, aggression in the workplace does not necessarily mean violence. Rather, it includes other nonviolent behaviors such as incivility (Schat \& Kelloway, 2005) and abusive supervision (Barling, Dupré, \& Kelloway, 2009; Zhang, Liu, Xu, Yang, \& Bednall, 2019). Aggression in the workplace appears to be particularly pervasive, as roughly $70 \%$ of Canadian and US employees surveyed on the topic indicate experiencing some type of verbal aggression or incivility at work (Barling et al., 2009).

Given that the effects of workplace aggression aren't felt only by those directly experiencing the act, but also by those who witness it (Schat \& Kelloway, 2005), workplace aggression can be particular problematic for organizations. Some evidence points to aggression being a catalyst for future deviant behavior (Park, Hoobler, Wu, Liden, Hu, \& Wilson, 2017). Additional consequences of coworker aggression include, but are not limited to, decreased commitment and increased turnover intentions (Schat \& Kelloway, 2005).

\section{Passive-Aggressive Behavior}

Aggressive behaviors can be classified into an approach-avoidance framework, which provides the ability to better classify aggressive behaviors based on what type of reaction they elicit, such as anger (i.e. approach) or anxiety (i.e. avoid) (Ferris et al., 2016). As passivity is typified by the absence of action, it then stands to reason that passive-aggression can be classified as an avoidance motivated type of aggression. The term passive-aggressive seems to be an oxymoron, but it describes the conflict that creates the behavior (Binning \& Wagner, 2002). The behavior is aggressive in that it reflects feelings of anger and hostility, and passive in that it includes feelings of fear and anxiety that keep the individual from acting on their aggression (Binning \& Wagner, 2002).

Binning and Wagner define the behavior by explaining that "passive expressions of aggression involve withholding actions with the intention of harming someone or an organizational entity" (2002). Simply stated, passive-aggressive behavior is the absence of action with the intention to do harm. Johnson and Klee (2007) provide a list of passive-aggressive behaviors, which include behaviors such as "verbal passivity, indirect and physically passive behaviors, action avoidance, ... obstructionism, and passive deceit" (see Johnson \& Klee, 2007, p. 131). It is worth noting that passive-aggressive behavior can also be viewed as a personality disorder. However, that is outside of the scope of this research. Following previous work on the topic, this research focuses on isolated acts of passive-aggression perpetrated by an individual who otherwise does not meet the requirements for the personality disorder (Binning \& Wagner, 2002).

The current literature on passive-aggression casts a wide net to explore the behavior (e.g. Johnson \& Klee, 2007), necessitating further research. Johnson and Klee (2007) explore possible causes of passive- 
aggression, particularly in response to leadership style. One noteworthy finding they report is that an autocratic leadership style may be a precursor of passive-aggressive behavior, possibly due to its coercive nature and tendency for conformance. They also find that situations of powerlessness or loss of control are more likely to lead to passive-aggressive behavior. These can manifest in situations such as organizational change or even performance reviews (Johnson and Klee, 2007).

\section{Deviant Workplace Behavior}

Employee deviance is defined as "voluntary behavior that violates significant organizational norms and in so doing threatens the well-being of an organizations, its members, or both" (Robinson \& Bennett, 1995). This definition includes any act that voluntarily violates the norms of the organization to be a type of deviance. Although it is easy to confuse deviant behavior with unethical behavior, the focus of deviant behavior is on breaking organizational norms rather than rather than the law or societal norms (Robinson \& Bennett, 1995). While this distinction is important, it must be noted that some deviant behaviors, such as physical violence or theft, violate both organizational norms and the law.

Using the above definition, deviance only includes behaviors that threaten the well-being of the organization or its members. In their original explanation of deviant behavior, Robinson and Bennett (1995) do not consider minor violations of social norms to be deviant. The exclusion of minor violations would not allow for the classification of all passive-aggressive behavior to be deviant, because by nature of the act, passive-aggressive behavior may seem to be minor because the act is may be unnoticeable. To account for this, following the framework of Binning and Wagner (2002), this paper modifies the accepted definition (Robinson and Bennett, 1995) to include all voluntary behavior that intentionally violates organizational norms. This distinction is important, as passive-aggression can occur in the workplace in contexts where it might not be considered deviant. For instance, Johnson and Klee (2007) discuss passive-aggression in the context of political behaviors. If passive-aggression occurs as part of workplace politics that are considered normal by the organization, it would not be considered deviant by this definition. In other situations where norms are broken but the organization or society at large benefit, passive-aggression could possibly be categorized as constructive deviance (i.e. Warren, 2003).

The focus on a definition of deviant behavior that includes intent is important because 1) the severity of the act is subjective and 2) an act that seems minor at first may have a larger impact over time. For instance, the example illustrating this would be the of wearing incorrect attire to work (Robinson \& Bennett, 1995). The authors agree that it may be a norm violation, but do not define it as organizational deviance. While this act may seem minor, if it is an intentional violation of organizational norms, it is deviant behavior and could later have an impact on the organization. If an individual chooses to dress casually on a day when they know they are expected to formally present to clients, this may be an intentional violation of organizational norms. The idea of intent is not unique to passive-aggressive behavior. In other areas of research related to deviance, such as organizational misbehavior, intent is the focal point of the definition (Vardi \& Wiener, 1996). Organizational misbehavior is defined as "any intentional action by members of organizations that violates core organizational and/or societal norms" (Vardi \& Wiener, 1996). This definition is very similar to that of Robinson and Bennett (1995), the inclusion of intent withstanding.

\section{Integrating Frameworks of Deviant Behavior and Passive-Aggressive Behavior}

To understand how the framework of passive-aggressive behavior specifically fits within the framework of deviant behavior in organizations, it is necessary to first understand the Robinson and Bennett (1995) typology of deviant behavior. In it, deviant behavior is categorized based on the severity of the behavior ("minor versus serious deviance") and the target of the behavior ("interpersonal versus organizational deviance") (Robinson \& Bennett, 1995). The typology classifies deviant behavior into four types: property deviance, production deviance, political deviance, and personal aggression (Robinson \& Bennett, 1995).

Relying on the earlier definition of passive-aggressive behavior as the absence of action with the intention to do harm, examination of the above typology of deviant behavior reveals that passive- 
aggressive behavior can be found in any one of the four types of deviance. For example, production deviance could occur when the employee withholds work or effort, resulting in lowered productivity. A more serious type of behavior directed at the organization might involve neglecting to report or perform needed maintenance on essential machinery. Through deliberate inaction, the employee could potentially destroy company property or force a production shut down. Passive-aggressive behavior directed toward the individual can also exist in both minor and serious forms. The former could occur in a situation such as not informing a coworker about an important piece of information, while the latter might involve intentionally neglecting safety precautions to endanger the life of another employee. Since passiveaggressive behavior can occur as any type of deviance, a more specific framework is needed to identify the characteristics of passive-aggressive behavior to determine its antecedents.

Binning and Wagner (2002) present a model of behavior that identifies passive-aggressive behavior by looking at the difference between passive and active aggression, as well as the difference between overt and covert behavior. Active versus passive refers to how the deviant act is performed. Active categorizes any deviant behavior that is verbally or physically carried out. Passive, by contrast, is the lack of verbal or physical action, as it is the "withholding" of an action (2002). An example of this could include neglecting to respond to an email or failing to finish a project on time.

The second part of the framework is overt versus covert behavior (Binning \& Wagner, 2002). Overt behavior is any behavior that is conducted in a visible manner that can be observed by other people in the organization. Conversely, covert behavior is conducted in a manner that is meant to hide the behavior from observers. While like passive behavior in that it is difficult to identify, it is important to see the distinction between the two, as together they comprise passive-aggressive behavior (Binning and Wagner, 2002).

A third element of the typology that is not reflected in the model is the distinction between direct and indirect aggression (Binning \& Wagner, 2002). This distinguishes between behavior that is executed directly against an individual or organization versus that which first goes through either a co-perpetrator or co-victim. While it can be important in aggressive deviant behavior, either method can be used to engage in passive-aggressive behavior (Binning \& Wagner, 2002).

Using the above framework, behavior can be classified to determine whether or not it is passiveaggressive (Binning \& Wagner, 2002). In recognizing passive-aggressive behavior, the main features are that it is both passive and covert (Binning \& Wagner, 2002). As such, passive-aggressive behavior involves the concealed withholding of an action with the intention of causing harm to the intended target. An example of this would be when a supervisor asks for a piece of information and the employee denies having it. While this type of behavior may appear to be minor compared to active or overt forms of aggression, passive-aggressive behavior can be insidious and, in certain instances, can quickly escalate to something more serious.

The target of a behavior is important in understanding deviance, because there is a difference between the types of deviance individuals engage in (Bennett \& Robinson, 2000). That is, those who engage in deviant behavior against the organization do so for a different reason than those who act against an individual in the organization (Bennett \& Robinson, 2000). Therefore, while passive-aggressive behavior is defined in terms of overt/covert and active/passive, it is important to distinguish that the target, either an individual or the organization, is a consideration that must not be overlooked. As the examples of passive-aggressive behavior illustrate, it is possible for it to occur in either situation. Based on the different motivations for the choice of target in deviant behavior (Bennett \& Robinson, 2000), it then logically follows that there will be different motivational factors for the choice of target for passiveaggressive deviant behavior.

\section{Antecedents of Deviant Behavior}

By examining what factors contribute to deviant behavior overall, and what antecedents have been empirically shown to predict such behavior, it is possible to build upon this literature and utilize it to propose factors that may influence passive-aggressive behavior. 
Throughout the deviance literature, there are three types of antecedents which have garnered attention (Bennett \& Robinson, 2003). One of the most empirically supported types, reaction to experience, looks at how employees respond to emotional stimuli such as frustration or perceived injustice (Bennett \& Robinson, 2003; Park et al., 2017). These situational stimuli are also tied to workplace aggression (Fox \& Spector, 1999). The second type, individual personality, considers personality traits such as dispositional aggressiveness, negative affectivity, and the Big Five personality traits. Similarly, research on workplace aggression has looked to personality traits such as anger, anxiety, and locus of control (Fox \& Spector, 1999) to explain the causes of aggression.

In the efforts to use personality to link individual traits to deviant behaviors, there has been limited success, with the exception of the use of the Big Five personality factors (Bennett \& Robinson, 2003; Lee, Ashton, \& Shin, 2005). Lee, Ashton, and Shin use the Big Five personality traits to find correlations between personality and anti-social behavior, in which they include deviant behavior (2005). While previous attempts to link personality to deviant behavior showed little result (Bennett \& Robinson, 2003), Lee et al. find support for extraversion and anti-social behavior. They posit that this may be due to the "high level of energy and boldness that characterizes extraversion" (Lee et al., 2005, p. 93). Other traits that have been associated with extraversion include assertiveness and being active (Barrick \& Mount, 1991). Extraversion has been linked to anti-social behaviors targeted toward both individuals and the organization (Lee et al., 2005), suggesting that there may be promise in further examination of these personality traits and deviant behavior.

The third, and final, antecedent type is adaptation to social context, which looks at deviance as a response to modeling or social learning (Bennett \& Robinson, 2003). Other proposed antecedents which exist for deviant behavior involve factors such as person-organization value congruence, generalized value of loyalty and duty, personal circumstance, opportunity, control systems, organization culture, cohesiveness, and goals for organization directed misbehavior (Vardi \& Wiener, 1996). This is just a short listing of a myriad of potential antecedents of deviant behavior.

Considerations of the social context to predict deviant behavior focus on what norms are violated. Norms can be understood based on group membership (Warren, 2003), so that an individual in an organization can operate under multiple sets of norms, such as norms of their immediate work group and norms of the organization. Since individuals may operate under conflicting norms, they are sometimes able to violate one set of norms without violating the other. From this, then, it is possible to argue that acts of deviance that harm the organization may be acceptable under group norms, making it easier for an individual to engage in organization-directed deviance. One study found that there was a relationship between coworker support and deviance, suggesting that when there are higher levels of coworker support, individuals feel that they can rely on their coworkers to "cover up" for them when they engage in deviant behavior (Liao, Joshi, \& Chuang, 2004).

There are also possible theoretical bases for the motivation of deviant behavior. For example, the Theory of Reasoned Action (Fishbein \& Ajzen, 1975) has been used to explain the motivation for deviant behavior (Vardi \& Weitz, 2002). Using this theory, it has been proposed that a negative attitude will lead to a negative behavior such as misbehavior. Furthermore, whether or not a person will act will is dependent on what they believe others will think about their behavior (Fishbein \& Ajzen, 1975; Vardi \& Weitz, 2002).

Empirical evidence supporting both situational factors and personality traits as predictors of deviant behavior lend support for looking at these behaviors not only to answer the question of when will deviant behavior occur, but also the question of what type of behavior is likely. The ability to recognize factors that might encourage a certain type of behavior will allow both researchers and practitioners to better understand deviant employee behavior. It is in this line of reasoning that this research seeks to better understand factors that lead to passive-aggressive workplace behavior.

\section{Proposed Antecedents of Passive-Aggressive Deviance}

Based on the findings of Lee et al. (2005), there is an empirical relationship between extraversion and deviant behavior. They associate boldness with extraversion (Lee et al., 2005), and others characterize it 
with assertiveness and action (Barrick \& Mount, 1991). These descriptions of extraversion suggest that individuals high in this personality trait will likely be more active in their deviant behavior than those who are low in extraversion. Using a dichotomous view of deviant behavior as either aggressive (active) or passive, it would then logically follow that extraversion would likely lead the individual to engage in an active form of deviance. Conversely, an individual low in extraversion may be inclined to engage in a less active or, passive, form of deviance.

Proposition 1: For individuals engaging in organizational deviance, extraversion will be positively related to engaging in an active (aggressive) form of deviance.

Another personality trait that may influence the tendency to engage in passive-aggressive behavior is self-monitoring. Studies on self-monitoring and cheating suggest that high self-monitors have a decreased likelihood of cheating when they are being observed (Covey, Saladin, \& Killen, 1989). High selfmonitors "control the images of self they project in social interaction (Snyder, 1986). In the area of deviance, the consideration of self-monitoring can be used to examine whether or not a person cares that they are caught engaging in deviant behavior. Logically, it might follow that high self-monitors will not want to engage in deviant behavior at all if they perceived that they would be judged negatively for it. However, the distinction is that high self-monitors are influenced more by how they are perceived than whether or not they are actually violating norms (Uddin \& Gillett, 2002), so high self-monitors will still engage in deviant behavior, they will just attempt to hide it. Using the framework of passive-aggressive behavior, the level of self-monitoring may predict whether an individual will engage in overt or covert deviance.

Proposition 2: For individuals engaging in organizational deviance, self-monitoring will be positively related to engaging in a covert form of deviance.

Using personality traits, it is suggested here that both a low level of extraversion and a high level of self-monitoring may make an individual more likely to engage in passive-aggressive deviant behavior. This is suggested because it is assumed that individuals who are low in extraversion will not be as likely to engage in active forms of deviance as those high in extraversion, and high self-monitors will choose to behave deviantly through covert means to ensure that they are able to preserve a good image they project to others. While personality traits may influence what kind of deviance an individual will engage in, empirically supported antecedents to deviant behavior also include responses to situational forces (Bennett \& Robinson, 2003).

One situation which may inspire covert and passive deviant behavior is the psychological contract breech. According to the theory of psychological contracts, "The term psychological contract refers to an individual's beliefs regarding the terms and conditions of a reciprocal exchange agreement between that focal person and another party" (Rousseau, 1989, p. 123). In the situation of the psychological contract, the individual believes that what they have done or provided for the organization deserves some type of reciprocity, even though the organization has not agreed to this contract. This type of contract relies heavily on an individual's assumptions that they will be rewarded for an act, even if it has not been explicitly agreed upon. If the contract is not fulfilled, this will change how the individual trusts the organization, as the organization has failed to fulfill its obligation to reciprocity (Rousseau, 1989).

The nature of passive-aggressive behavior is to withhold an action (Binning \& Wagner, 2002), so it is possible that passive-aggressive behavior can be instigated when an employee feels that the organization withheld that which they considered owed to them. This violation of the psychological contract frustrates the employee, and in an act of reciprocity, they then withhold something from the organization as a type of penalty. Due to the fact that the organization has not agreed to the contract, the individual cannot openly retaliate because the need for reciprocity is not readily apparent to anyone other than the individual. As a result, the retaliatory behavior will match the psychological contract breech in that it was unknown to others (covert). 
Proposition 3: For individuals engaging in organizational deviance, those who are reacting to a perceived violation of a psychological contract will be more likely to engage in passive-aggressive deviant behavior.

\section{FUTURE RESEARCH}

The propositions presented by this paper are the attempt to build upon the existing literature to further understand what drives a specific type of deviant behavior. The focus of this paper is on passiveaggressive deviance, but evidence supporting any or all of the above propositions would then also lend empirical support for understanding other types of deviant behavior. The focus of this paper is on the type of deviance that is, by far, the most difficult to identify because it is meant to be secret. By recognizing that non-action can be deviant and going a step further to understand what may lead to this type of behavior, we are closer to understanding deviant behavior as a whole.

There are, of course, limitations that must be addressed before substantial research can be conducted on passive-aggressive behavior. The greatest obstacle, by far, is in data collection. For deviance related data, there are three main sources: self-reporting, other reporting (i.e. coworkers or supervisors), and direct observation (Sackett, 2002). All three of these pose a challenge in obtaining accurate information about deviant behavior, but will likely stand as an even greater obstacle when surveying for passiveaggressive behavior. This is likely due to the very nature of passive-aggressive behavior - it is covert.

Despite the challenges related to empirically investigating passive-aggressive deviance, there is a great deal of potential for exploring this type of behavior. In their review of organizational deviance literature, Bennett and Robinson (2003) suggest that further emphasis needs to be placed on understanding deviance in situations other the blue collar settings, as this has been the case for many deviance studies. The study of passive-aggressive behavior in the workplace does not limit itself to any particular setting or group of settings. Rather, it is broadly applicable and will likely be found in any organizational setting due to the way passive-aggressive behavior can be carried out. One area in particular that could hold promise for research on passive aggressive behavior is white-collar office work that heavily utilizes individual employee computer terminals.

The examination of behaviors that arise out of new technological advances in the workplace is an area that holds potential for research on deviance (Bennett \& Robinson, 2003). While technology need not be present for a person to engage in passive-aggressive behavior, it does allow them more opportunity. For instance, technology can offer anonymity to an individual, creating an environment safe for covert activity. While there are some safeguards in place such as monitoring and activity logs, the availability of technology allows more opportunity for anonymous interaction because the technology acts as an intermediary for the behavior. Due to its prevalence and (to a certain degree) assumed anonymity, technology related deviance could be an area that holds great potential for research on passive-aggressive deviant behavior.

\section{CONCLUSION}

Types of deviance vary from study to study, but the central theme that ties them together is that deviant behavior is a violation of organizational norms that causes some type of harm (Robinson \& Bennett, 1995). Using a framework that categorizes deviant aggressive behavior as either active or passive and overt or covert, it is possible to examine various types of deviant behavior and begin to try to understand what causes them. It is the intention of this paper to take closer look at passive-aggressive deviance, a behavior that easily goes unnoticed but can also do a great deal of harm to the organization or individuals. By understanding what drives this specific type of behavior, we can also come closer to understanding the causes of deviant behavior as a whole. 


\section{REFERENCES}

Andersson, L. M., \& Pearson, C. M. (1999). Tit for tat? The spiraling effect of incivility in the workplace. Academy of Management Review, 24(3), 452-471. doi: 10.5465/amr.1999.2202131

Barling, J., Dupré, K. E., \& Kelloway, E. K. (2009). Predicting workplace aggression and violence. Annual Review of Psychology, 60, 671-692. doi: 10.1146/annurev.psych.60.110707.163629

Barrick, M. R., \& Mount, M. K. (1991). The big five personality dimensions and job performance: A meta-analysis. Personnel Psychology, 44(1), 1-26. doi: 10.1111/j.1744-6570.1991.tb00688.x

Bennett, R. J., \& Robinson, S. L. (2000). Development of a measure of workplace deviance. Journal of Applied Psychology, 85(3), 349-360. doi: 10.I037//0021-9010.85.3.349

Bennett, R. J., \& Robinson, S. L. (2003). The past, present, and future of workplace deviance research. In J. Greenberg (Ed.), Organizational Behavior: The State of the Science, 2nd edition. Mahwah, NJ: Lawrence Erlbaum.

Binning, J. F., \& Wagner, E. E. (2002). Passive-aggressive behavior in the workplace. In J. C. Thomas, \& M. Hersen (Eds.), Handbook of Mental Health in the Workplace. Thousand Oaks, CA: Sage Publications.

Crino, M. D. (1994). Employee sabotage: A random or preventable phenomenon? Journal of Managerial Issues, 6(3), 311-330. https://www.jstor.org/stable/40604030

Covey, M. K., Saladin, S., \& Killen, P. J. (1989). Self-monitoring, surveillance, and incentive effects on cheating. Journal of Social Psychology, 129(5), 673-679. doi: 10.1080/00224545.1989.9713784

Fishbein, J., \& Ajzen, I. (1975). Belief, Attitude, Intention, and Behavior: An Introduction to Theory and Research. Reading, MA: Addison-Wesley.

Fox, S., \& Spector, P. E. (1999). A model of work frustration-aggression. Journal of Organizational Behavior, 20(6), 915-931. https://www.jstor.org/stable/3100373

Greenberg, J. (1990). Employee theft as a reaction to underpayment inequity: The hidden cost of pay cuts. Journal of Applied Psychology, 75(5), 561-568. doi: 10.1037/0021-9010.75.5.561

Johnson, N. J., \& Klee, T. (2007). Passive-aggressive behavior and leadership styles in organizations. Journal of Leadership and Organizational Studies, 14(2),130-142. doi: $10.1177 / 1071791907308044$

Lee, K., Ashton, M. C., \& Shin, K. (2005). Personality correlates of workplace anti-social behavior. Applied Psychology: An International Review, 54(1), 81-98. doi: 10.1111/j.14640597.2005.00197.x

Liao, H., Joshi, A., \& Chuang, A. (2004). Sticking out like a sore thumb: employee dissimilarity and deviance at work. Personnel Psychology, 57(4), 969-1000. doi: 10.1111/j.17446570.2004.00012.x

Park, H., Hoobler, J. M., Wu, J., Liden, R. C., Hu, J., \& Wilson, M. S. (2017). Abusive supervision and employee deviance: A multifoci justice perspective. Journal of Business Ethics, 1-19. doi: 10.1007/s10551-017-3749-2

Robinson, S. L., \& Bennett, R. J. (1995). A typology of deviant workplace behaviors: A multidimensional scaling study. Academy of Management Journal, 38(2), 555-572. doi: 10.5465/256693

Rousseau, D. M. (1989). Psychological and implied contracts in organizations. Employee Responsibilities \& Rights Journal, 2(2), 121-139. doi: 10.1007/BF01384942

Schat, A. C. H., \& Kelloway, E. K. (2005). Workplace aggression. In J. Barling, E. Kelloway, \& M. Frone (Eds.), Handbook of Work Stress, (189-218). Thousand Oaks, CA: Sage Publications, Inc.

Sackett, P. R. (2002). The structure of counterproductive work behaviors: Dimensionality and relationships with facets of job performance. International Journal of Selection and Assessment, 10(1-2), 5-11. doi: 10.1111/1468-2389.00189

Snyder, M. (1986). Public Appearances/ Private Realities. New York: W.H. Freeman and Company.

Tepper, B. J. (2000). Consequences of abusive supervision. Academy of Management Journal, 43(2), 178-190. doi: 10.2307/1556375

104 Journal of Organizational Psychology Vol. 19(4) 2019 
Tepper, B. J. (2007). Abusive supervision in work organizations: Review, synthesis, and research agenda. Journal of Management, 33(3), 261-289. doi: 10.1177/0149206307300812

Uddin, N., \& Gillett, P. R. (2002). The effects of moral reasoning and self-monitoring on CFO intentions to report fraudulently on financial statements. Journal of Business Ethics, 40(1), 15-32. doi: 10.1023/A:1019931524716

Vardi, Y., \& Weitz, E. (2002). Using the theory of reasoned action to predict organizational misbehavior. Psychological Reports, 91(3), 1027-1040. doi: 10.2466/pr0.2002.91.3f.1027

Vardi, Y., \& Wiener, Y. (1996). Misbehavior in organizations: A motivational framework. Organizational Science, 7(2), 151-165. doi: 10.1287/orsc.7.2.151

Warren, D. E. (2003). Constructive and destructive deviance in organizations. Academy of Management Review, 28(4), 622-632. doi: 10.5465/amr.2003.10899440

Zhang, Y., Liu, X., Xu, S., Yang, L. Q., \& Bednall, T. C. (2019). Why Abusive Supervision Impacts Employee OCB and CWB: A Meta-Analytic Review of Competing Mediating Mechanisms. Journal of Management. doi: 10.1177/0149206318823935 